\title{
Contrastive Analysis of Primary School and College Classroom Talks: The Sinclair-Coulthard 'Birmingham' Model Approach
}

\author{
Caixia Si \\ Huanghe Science and Technology College \\ Zhenghou, China
}

\begin{abstract}
With a more accurate picture of natural classroom discourse, teachers and researchers are in a better position to evaluate what goes on in the classroom. In this paper, using the collected data, I will try to analyze primary school and college classroom talks and make a comparison between the two under the direction of the Sinclair Coulthard 'Birmingham' model.
\end{abstract}

Keywords-discourse analysis; the Sinclair - Coulthard 'Birmingham' Model; transaction; exchange; move; act

\section{INTRODUCTION}

Arising out of a variety of disciplines, including linguistics, sociology, psychology, and anthropology, discourse analysis has built a significant foundation for itself in applied linguistics. Because discourse analysis focuses on language in use, on how real people use real language, it is of immediate interest to language teachers and researchers, and classroom talk analysis becomes very popular, because it can answer the question of how talk follows regular patterns in a wide range of different situations, how such complex areas as intonation operate in communication, and so on. I hope this paper can reveal the nature of classroom talks of different levels to some extent.

\section{THE SinClAIR - COUlTHARD 'BIRMINGHAM' MODEL}

One influential approach to the study of spoken discourse is that developed at the University of Birmingham. Sinclair and Coulthard (1975) found in the language of traditional native-speaker school classrooms a rigid pattern, where teachers and students spoke according to very fixed perceptions of their roles and where the talk could be seen to conform to highly structured sequences. Sinclair and Coulthard offered a hierarchical model where smaller units can be seen to combine to form larger ones. The bare bones of the hierarchy can be expressed as follows:

TRANSACTION

1 EXCHANGE
1 $\mathrm{MOVE}$
1 $\mathrm{ACT}$

The Sinclair-Coulthard 'Birmingham' model is useful for describing talks of the classroom, and it captures patterns that reflect the basic functions of interaction in the classroom.

\section{AN ANALYSIS OF PRIMARY SCHOOL CLASSROOM TALKS}

My classmates and I altogether collected data concerning primary school classroom, middle school classroom, and college classroom interactions by means of mp3 or video. Then from each data we chose several phases of talks and transcribed them. The following is my analysis of these data by using the Sinclair - Coulthard 'Birmingham' model. school.

Firstly look at an extract of classroom talks of primary

\section{( $\mathrm{T}=$ teacher, $\mathrm{S}=$ student)}

$\mathrm{T}: / / / \ldots .$. (The teacher shows a photo to the class) OK... Now then...Look at this picture. Who is he? Hands up. (most of the pupils raise their hands, even some of them stand up in order to get the chance) You, please./

$\mathrm{S} 1:$ He is Zhou jielun./

$\mathrm{T}$ : Very good, sit down please.//Do you like him?/

S2: yes, I do./

T: Yes, I do. Very good. Sit down please.// Do you want to write a letter to zhou jielun?/

\section{S3: yes, I do./}

T: yes, I do, very good, sit down please.// Do you want to send postcards to Zhou jielun?/

S4: yes, I do./

T: very good, thank you, sit down, please.// Do you often write letters?/

S5: No ...

T: No, I don't.

S5: No, I don't./ 
This is only a short extract of classroom talk, but nonetheless, a clear pattern seems to emerge. The first thing we notice is that this extract seems to have a completeness with the teacher saying 'OK... Now then...' This is the clear signal that the teacher gave to his students of the beginning of a new phase. According to Sinclair and Coulthard, 'OK... Now then...' serves as the framing move. The two framing moves, together with the question and answer sequence that falls between them can be called a transaction. (I use '///' to illustrate the boundaries of a transaction in the above data.)

From the above we can see the characteristics of classroom talks between teacher and student are:

- The teacher usually uses some strategies to start the transaction, for example, showing the students a picture. That's because the pupils' attention span is rather short.

- An exchange almost has strictly three moves.

- The teacher's initiating question is rather simple and has a fixed answer. In response, the teacher usually played the vital role of telling the students whether their answers are right or wrong.

- The students' desire to answer the question is quite high; they show their interest to answer the teacher's questions.

\section{CONCLUSION}

In the above, we have compared classroom talks of primary school and college. We can see obviously the difference.

- In primary school, an exchange almost has strictly three moves. While at college, an exchange almost doesn't have strictly three moves; usually it has the initiation, the response, but seldom the teacher's evaluation or comment as a follow-up.

- In primary school, the classroom talk is teacherdominated. While at college, the teacher and the students are more equal speakers.

- In primary school, the teacher played the vital role of telling the students whether their answers are right or wrong. While at college, the teacher play the vital role of challenging the student's answers, or expanding the talk by asking more questions to make the students talk more.

All in all, after we have commanded these characteristics by using discourse analysis, we are in a better position to teach students according to their different ages.

\section{REFERENCES}

[1] Ellis Rod. "The study of Second Language Acquisition" (English Version). [M]. Shanghai: Shanghai Foreign Language Education Press, 1997.
[2] McCarthy Michael. "Discourse Analysis of Language Teachers" (English Version). [M]. Shanghai: Shanghai Foreign Language Education Press, 2004.

[3] Xu Jiujiu. Discourse Analysis for Twenty Years [J]. Foreign Language Teaching and Research. 1995(5). 